\title{
Emergency Remote Foreign Language Learning: First Reflections
}

\author{
Bondarenko O. R. \\ Historical and Archival Institute, Russian State University for the Humanities, Russia
}

Received December 4, 2020; Revised January 11, 2021; Accepted February 18, 2021

\section{Cite This Paper in the following Citation Styles}

(a): [1] Bondarenko O. R. , "Emergency Remote Foreign Language Learning: First Reflections," Universal Journal of Educational Research, Vol. 9, No. 2, pp. 390 - 397, 2021. DOI: 10.13189/ujer.2021.090215.

(b): Bondarenko O. R. (2021). Emergency Remote Foreign Language Learning: First Reflections. Universal Journal of Educational Research, 9(2), 390 - 397. DOI: 10.13189/ujer.2021.090215.

Copyright $\bigcirc 2021$ by authors, all rights reserved. Authors agree that this article remains permanently open access under the terms of the Creative Commons Attribution License 4.0 International License

\begin{abstract}
This paper responds to the recent dramatic realignment of teaching processes prompted by the pandemic in terms of speed and effort. The phenomenon was labelled "emergency remote teaching" by Hodges and a team of scholars to distinguish the abrupt shift to online study during the pandemic from systemic online teaching. Since the pedagogical context regarded is unprecedented and has, to date, received minimal scholarly attention, the author takes the liberty of sharing her small-scale exploratory experiences. The goal of this empirical research was to gauge first-hand tertiary students' perceptions of the significant changes that took place in foreign language learning routines this year. The researcher was interested in students' general attitudes about the sudden shift in learning environment from physical face-to-face learning in the classroom to remote learning, as well as the restrictions imposed by it and students' readiness to continue remote language learning if necessary in the future, as a high degree of uncertainty about future prospects remains. To meet this goal, a questionnaire was offered to students of a bachelor's degree level course in foreign regional studies at the Russian State University for the Humanities at the conclusion of the spring term in June 2020. The results were interpreted within the framework of the generations theory and computer-mediated communication theory. Findings indicate that most respondents were hesitant about remote language learning and preferred that it be offered in combination with physical face-to-face instruction.
\end{abstract}

Keywords Emergency Remote Learning, Face-to Face Learning, Computer-Mediated Communication,
Generation Z, Study in Pandemic, Survey

\section{Introduction}

The study described in this paper represents a response to the dramatic and urgent changes in the format and methods of tertiary education that the world encountered in 2020 due to the COVID-19 pandemic. Whereas distant, hybrid, and e-learning courses were able to continue almost seamlessly during the quarantine that depeopled campuses, educators teaching off-line courses were forced to suddenly transform those courses for the virtual environment, which entailed some extreme reconceptualization and urgent actions. The resulting learning context can be labeled "emergency remote learning” (ERL). ERL during the pandemic quarantine was characterized by specific features that differentiate it from regular computer-mediated remote learning:

- It was created through an urgent and sudden transition to a distant form of learning.

- Whereas pre-pandemic remote forms of learning could be integrated with face-to-face (F2F) learning, ERL was an uncontested, no-alternative structure that replaced traditional contact language learning-a compulsory necessity imposed by circumstances with no regard for individual learning preferences and styles, which could be frustrating for students.

- The course of study had to be hastily redesigned and adapted to new modes of communication, which led to stressful situations for students and faculty. 
- The situation was aggravated by the social and physical isolation of students who could contact their peers and friends online but not face to face.

- The unprecedented shift to ERL had no prior analogues to draw on for guidance.

The English-as-a-foreign-language (EFL) course for would-be bachelors specializing in foreign regional studies in the Russian State University for the Humanities (RSUH) underwent such a transition to ERL. In March 2020, the university administration allowed a one-week break in classes for students, who lived throughout Russia, to travel back to their homes and for faculty to modify in-person classes, including F2F language classes, to accommodate the online environment.

After the quarantine set in, both faculty and students were immersed in the ERL process, which was able to proceed uninterrupted due to the provision of the Zoom and Skype platforms. Peer groups formed in September 2019 or earlier contained students who knew each other and had had F2F interactions before the ERL shift, which relieved the stress of the transition to some extent. However, the expediency of the situation left no time for the integration of technology into classroom practices. Some faculty lacked adequate ICT skills or were not properly equipped with access to distant learning platforms when the need to transform classes arose. Therefore, learning, teaching, and mastering remote technologies occurred simultaneously. That is why the process entailed not only physical relocation for participants but deeper consequences: (1) a radical change of the learning environment, including distant modes of communication, different access to learning materials, and a change in quality of Internet connection, as the quality of connections varies across Russia, (2) the sensory thirst of predominantly sensory learners, and (3) technically impaired control of students by a teacher, to name a few. In this context the foreign language learning process would depend to a great extent on students' motivation, flexibility, digital competence, and personal stance.

\section{Literature Review}

The computer-mediated communication (CMC) theory examines the ways in which human behavior is maintained or altered by the exchange of information through machines [1]. December [2] defined it as "the process by which people create, exchange, and perceive information from telecommunication networks that facilitate encoding, transmitting, and decoding messages." A plethora of literature on CMC elucidates its role in the sphere of social networking [3, 4] and text-based interactions that dominate the Internet [5]. Research on the latter has demonstrated that the CMC theory not only promotes relationship building but also can be used for professional purposes. Moreover, the CMC theory increasingly has been used for educational purposes [6] or served as the subject of academic learning [7]. The CMC theory was described by Caplan [8] as "characterized by beliefs that one is safer, more efficacious, more confident, and more comfortable with online interpersonal interactions and relationships than with traditional (F2F) social activities." This assertion is difficult to contradict and may predict expected support for ERL from students.

On the other hand, the CMC theory also can pose time-consuming technical and logistical problems [9].

One of the illuminating frameworks applied to the CMC theory is the social presence theory [10], which highlights the fact that CMC media differ in their flow of various verbal and non-verbal cues that impact communication. According to Walther [11], the fewer cue systems supported, the less warmth and involvement communicators experience. As Walther argued, the lack of nonverbal CMC cues may lead to self-focusing instead of involvement. Some researchers consider CMC to be relatively depleted emotionally because of the lack of cues [12]. These factors can be crucial in the context of exclusively remote, non-contact academic communication.

The impact of technological media on human behavior, relationships, and self-presentation already studied by scholars [13] can help to reveal perceptions and attitudes of ERL actors. Indisputably, digital remote learning currently is a full-fledged, highly demanded mode, but it normally complements rather than replaces traditional F2F learning. The COVID-19 situation demanded total replacement of such in-person sessions with exclusively online distant classes and, since there had been no precedent for such actions, it posed issues such as the emergent transfer from F2F vital communication to remote learning, acceptability of ERL for students, and the required adaptability of students and tutors to the new conditions of instruction.

Under those circumstances certain student reactions and behaviors could be predicted to some degree of probability by the generation theory. Today's higher education students, born after 1995, are part of Generation $\mathrm{Z}$, which has been characterized by scholars as a very social and collective-conscious generation, more resilient than millennials, that values interpersonal interaction [14, 17]. They like to collaborate [15], are true “communaholics” and "dialoguers” [16]. Technologically savvy [14], "Gen-Zers” are quite at home in cyberspace [15]. As evidenced by some studies, this generation of self-learners is more comfortable mining knowledge online than in traditional educational institutions [16]. These characteristics suggest a high likelihood that these students hold positive and preferential attitudes toward ERL contexts.

Modern scholars confirm that attitudinal outcomes in the ERL situation are of interest both for students and faculty [18]. For this reason, the goal of this small-scale 
study was to investigate the attitudes of students toward the unique experience of ERL, including online activities, in the EFL course during the 2020 pandemic.

\section{Materials and Methods}

The researcher sought to discover students' perceptions of ERL, their preferred synchronous communication tools for language learning, the online learning activities they found appealing, the offline F2F activities they missed most during the period of ERL, and their sentiments about the prospect of studying EFL online in the future. Thus, the research questions were grouped according to three main topics: (a) students' perceptions about remote learning platforms; (b) students' favorite remote versus F2F class activities and their correlation, if any; and (c) students' attitudes toward the likelihood of studying under ERL in the future.

This research was conducted at the RSUH in Moscow in March-June 2020. The study population comprised 18to 20-year-old pre-career students from the full-time day department who were working toward a bachelor's degree and specializing in foreign regional studies. ERL was provided via Skype in the reduced audio-conferencing mode. Students participated in class sessions from all over Russia and could see and hear their instructor, but their instructor could only hear them.

This study was underpinned theoretically by the computer-mediated communication theory, social influence theory, media richness theory, and the theory of generations.

The methods applied included observation, differential analysis, and surveying.

Participants completed an online 8-question survey based on the three topics outlined in the research questions in June 2020, at the end of the term of study. Elaboration on the questionnaire, the online survey, and computation of the results were all completed using Google Forms. The main findings are embodied in diagrams depicted in Figures 1-5. Each anonymous response was assigned a number, coded, and analyzed.

In addition to the survey, some indirect data indicating students' attitudes toward ERL were gathered and processed quantitatively. Such indicators included (1) average attendance rates for contact F2F EFL classes during the autumn term and rates for ERL classes during the spring term by the same students, (2) the EFL personal achievement score of each student in the autumn and spring terms, and (3) the completion rate or COR (percentage of students who successfully completed the course for the year). Academic points were awarded to students for their oral performance and written papers according to the CEFR descriptors and RSUH requirements. Since these data were related to students' interests, motivation, and effort, they were considered indicative of students' attitudes toward the ERL of EFL and relevant to this study.

\section{Results and Discussion}

According to the author's observations, students exhibited signs of depressed spirits at the beginning of the ERL period. However, regular online sessions and the combined use of synchronous and asynchronous instruments during class sessions and between them resulted in more stable, cheerful, and productive atmospheres for learning, which was reflected in the survey responses.

The first two questions of the questionnaire were as follows: (1) What online learning platforms have you used so far during the lockdown? (2) Which platform do you find most user-friendly? According to the responses, students learned mainly via Skype (64\%), or Skype in combination with other distant videoconferencing systems, depending on the discipline, for example Skype and Zoom (about 7\%) and Skype, Zoom, and Discord (about 7\%). Most students named Skype the most user-friendly service (79\%), followed by Discord (14\%). According to the social influence theory, the users' perceptions of the quality of a medium depends on their experience with that medium [19], so we can infer that students found the transition to Skype and the continued educational process chiefly satisfactory and acceptable, despite the emergency circumstances under which they experienced the radical format change.

\section{Which platform do you find the most efficient for language learning results?}

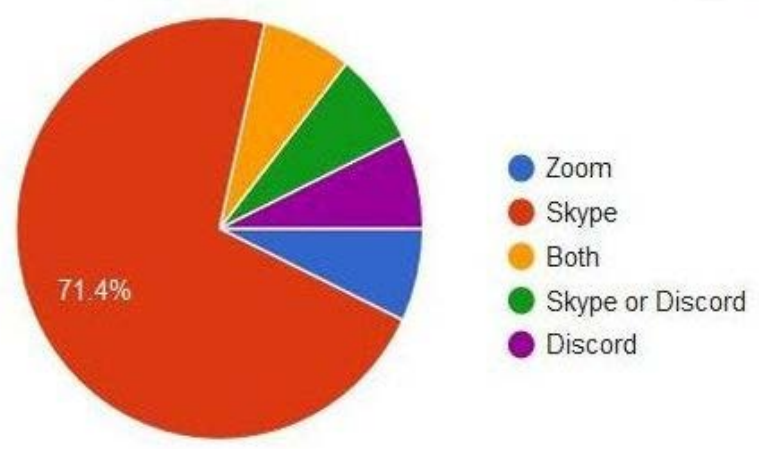

Figure 1. Student preferences for language learning platforms

Moreover, the majority of students (71.4\%) perceived Skype to be the most efficient platform for learning a foreign language. About $7 \%$ of respondents indicated that Skype shares this ranking with Discord, while another 7\% gave preference to both Skype and Zoom (Fig. 1). Question 7 asked students if they found the Skype platform effective for learning EFL. It is noteworthy that, while most respondents (57\%) answered in the affirmative, and none of the students indicated that it was not effective, 
an impressive number of students (43\%) deemed the ERL context for studying EFL through Skype less effective than traditional live classes. This perception can be accounted for with the media richness theory. As a popular model of computer-mediated communication, this theory states that the quality of communication depends on the number of various cues received by interlocutors. Thus, the richest mode, as evidenced by Daft and Lengel [20], is F2F communication because it involves multiple-cue systems, simultaneous sender-receiver exchanges that provide immediate feedback, and message personalization. This opinion is substantiated by other research, proving that an abundance of expressive and interpersonal cues is likely to cause more positive impressions in F2F interactions [12]. Students evidently found the effect produced by the lack of cues provided through Skype audio language class less favorable than the effect of the multiple cues available during F2F sessions.

Moreover, the lack of cues may even lead to an increased psychological distance between participants and, thus, hamper communication, as Rutter argued [21]. Analysis of responses to questions 4 and 5 may further clarify the causes of such attitudinal downshifting.

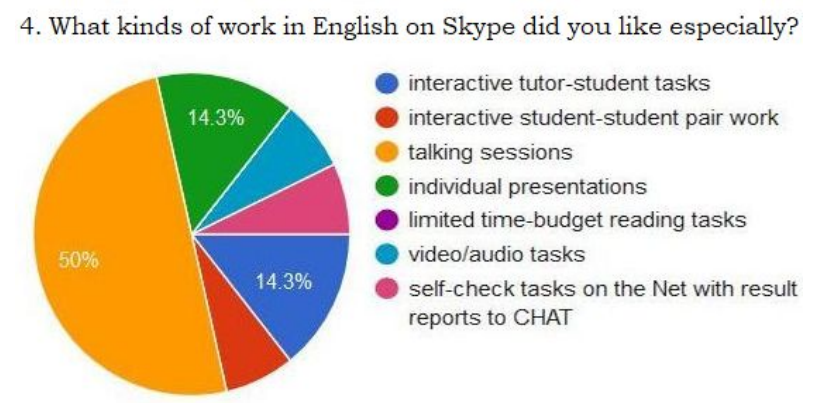

Figure 2. Skype EFL activities preferred

Further probing into ERL of the English language through Skype revealed some interesting activity preferences. Half the respondents spoke in favor of talking sessions during Skype classes (e.g., impromptu comments on a topic chosen by a student on the spot); additionally, interactive tutor-student tasks (14.3\%) and individual presentations (14.3\%) both received noticeably greater evaluations than the remaining options (Fig. 2). Interactive tutor-student tasks involved discussions of stories and films, completion tasks like "Finish the famous public figure's proverb or quotation," and reaction tasks, such as "React to the following situation with a suitable proverb," along with similar activities.

To understand and explain the responses presented in Figure 2, responses pertaining to the seven activity options provided in question 4 (see Figure 2) were analyzed through the prism of interactivity. The top favorite online activities involved student-student interactions (talking sessions, individual presentations) and tutor-student interactions (tutor-student tasks), that is, "humanized" or social person-to-person interactions. The least popular online activities are characterized by "dehumanized" cognitive interactions, like studentvideo/audio files, student-text (reading tasks), and student-Internet quiz/test/exercise (self-check tasks). Commonly popular with students, pair work within the ERL modality was favored by only $7 \%$ of respondents. Since Skype does not provide an option for autonomous grouping, students had to use the mobile phone WhatsApp application for this function. To summarize, students held the most positive attitudes toward "humanized" ERL interactive activities that developed oral speech.

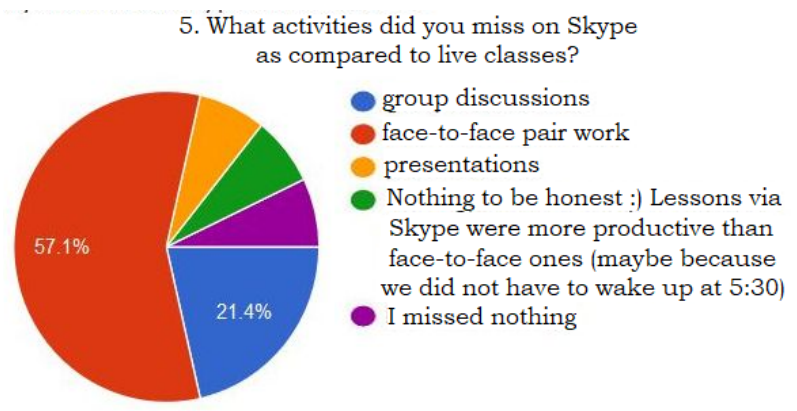

Figure 3. Face-to-face activities students missed while learning through Skype

About $14 \%$ of respondents noted they did not miss any activities from traditional live classes while studying online. However, despite students' reported overall satisfaction with ERL on Skype, they did indicate missing some traditional F2F activities. As illustrated in Figure 3, the majority missed the F2F pair work that takes place in the traditional contact environment. Second on the nostalgic scale was group discussion (discussing current news, topical issues, home-read stories, home-watched films). Individual presentations, although acknowledged as one of the online favorites (Fig. 2), were still mentioned as missed in the F2F environment by about $7 \%$ of respondents, as compared to presentations in traditional contact classes. These data correlate with the data in Figure 2: student pair work was not popular in the ERL format with the majority; logically, this activity was identified by a majority of students as an activity they missed from the traditional F2F format. Apart from that, a correlation existed between the seemingly contradictory data about two similar activities-talking sessions and group discussions-which were named among ERL favorites by every second respondent, while group talking in the F2F context, at the same time, was missed by every fifth respondent.

To examine the reason for this correlation, a differential analysis was employed, which enables the determination of differential features of similar phenomena. For this purpose, pair work and group discussion activities were scrutinized as forms of communication in two different contexts: ERL class and F2F contact class. Despite a 
number of similar features (interactivity, audio or audio-visual modality, eye contact in audio-visual modality of ERL), talking in the ERL context has a few differential markers, that is, features typical in this context but not characteristic of this activity in the F2F context, such as mediation by a messenger, with consequences like technical interference (mike buzzing, echo effect, fading sound, disconnection), mono or bi-sensory communication (audio or video connection), and no spatial involvement. Conversely, F2F contact talking has other differentials, such as direct communication without technical mediators; multisensory communication involving eye contact, body language, and other non-verbal cues; haptic sensations; and spatial dynamism with meaningful proxemics and change of attitudes. In addition, as noted by Sproull and Kiesler [12], computer-mediated communication "is depleted emotionally." It can be inferred from these details that the differential qualities of group discussion in the contact class are more attractive, cue-richer, and non-compensatory online for students and, hence, were missed in the ERL class.

6. How did you manage to be 'present in Skype class'?

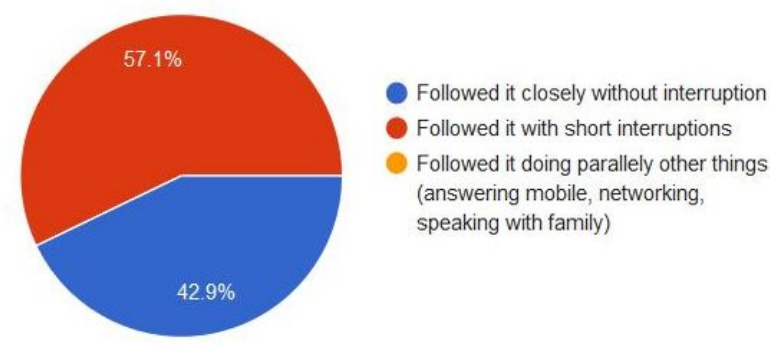

Figure 4. Attendance style self-assessment

Question 6 was aimed at eliciting students' critical self-assessments of their ERL discipline in a virtual classroom. As depicted in Figure 4, most students honestly confessed "short interruptions" in their presence, but none allegedly answered their mobile phones or spoke with family members during class. The latter finding rests on the students' conscience, bearing in mind occasional silent responses, the long duration of remote classes (3 hours with a 10-minute break), and the remarkable multi-tasking ability of Generation Z [22].

8.Would you like to continue studying English at a distance?

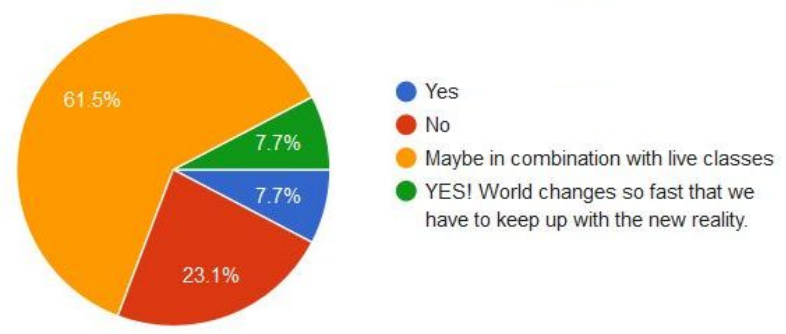

Figure 5. Attitudes toward remote language learning in the future
Responses to the last question demonstrated that only a minority of students (15.4\%) were firm proponents of remote EFL learning; firm opponents constituted about $23 \%$, while the majority (61.5\%) may be open to remote learning if combined with in-person live instruction (Fig. 5). This cautious attitude can be attributed to multiple factors. First, the direction of the transition from F2F to CMC sessions, rather than in the opposite direction, and the emergency circumstances under which it occurred, may have played a crucial role in influencing students' attitudes on this issue. As evidenced by other investigations, when communicators have already had an alternative media experience (live F2F, for example), computer-mediated communication "should be the least satisfying” [23]. That was the case in this study. By contrast, a survey of students conducted in Uruguay showed that after three years' experience of uncontested remote language learning, 93\% of students stated they liked learning English remotely [24]. Second, as some scholars have argued, it is F2F communication that enhances feelings of togetherness [25], one of the main values of Generation Z. Those feelings may have been poignantly missed during lockdown ERL sessions.

Nearly every fourth student spoke out unequivocally against remote language learning, which was rather unexpected from digital generation students and requires interpretation. Such opinions may, in part, be caused by the discipline specificity of the English language itself that implies, by default, multichannel communication, which could not be provided under the circumstances. Moreover, the rejection of ERL may be underpinned, also in part, by some deep cultural characteristics of Russian learners explicated in terms of Hall's high/low context cultures theory [26]. Russians are qualified by scholars as a high-context nation $[27,28]$, meaning it is a nation in which features such as favoring direct contact and giving importance to non-verbal language and touch are inherent [29]. ERL deprived Russian learners of all this and, as such, may have aroused the negative attitude mirrored in the survey.

The nostalgia for rich-in-cues foreign language communication caused by ERL can be indirectly confirmed by information received within this study and presented further as a short descriptive summary. These are findings about students' comparative extracurricular activities, that is participation in non-mandatory creative and scholarly academic events like contests, festivals, round-table discussions or scientific readings in English offline, before the pandemic in the fall of 2019, and online during the pandemic fall of 2020. The data collected involved, besides the author, seven colleague tutors instructing in English as a foreign language at the same department. The objects of computation were (a) the number of the tutor's course groups participating, and (b) the average number of participating students per tutor's course group. The results show that during the ERL 
period one tutor's participating groups decreased, 4 tutors' groups remained the same as during the offline period, and three tutors' participating groups increased in number. The average count of participating students per tutor's course group during the ERL extracurricular events demonstrated two declines, one same-number result, and four tutors' average participants number increase. The conclusion that suggests itself is that deprived of fully-sensory communication in the ERL language classes students may have sought to compensate for communication cues deficit by extending a range of their foreign language activities.

Some other indirect data indicating students' attitudes toward ERL were gathered and processed quantitatively. The average attendance rates in contact EFL classes during the autumn pre-pandemic term and in the ERL classes during the spring term by the same students were computed and are outlined in Table 1.

Table 1. Average attendance per person per group

\begin{tabular}{|c|c|c|}
\hline Students & Autumn term & Spring term \\
\hline First-year group & $91 \%$ & $85 \%$ \\
\hline Second-year group & $62 \%$ & $62 \%$ \\
\hline
\end{tabular}

As the data show, ERL EFL classes during the lockdown were not marked either by a sharp upsurge, as could be expected due to the convenience of study from home, or by a decline, which may have resulted from flagged motivation. In one group it remained at the same level, while in the other group it decreased slightly. The slight decrease was caused by some students who fell ill taking sick leave. By and large, the shift to ERL per se did not cause any disastrous fall in attendance, which means that the emergency situation was not regarded by students as an excuse to stay away from their remote tertiary classes.

Table 2. End-of-Term EFL Achievement Results in Group 1 (second-year students)

\begin{tabular}{|c|c|c|c|}
\hline № & Student & $\begin{array}{c}\text { Autumn 2019 } \\
\text { (F2F class) } \\
\text { term scores }\end{array}$ & $\begin{array}{c}\text { Spring 2020 } \\
\text { (ERL class) } \\
\text { term scores }\end{array}$ \\
\hline 1 & Al. & 64 & 74 \\
\hline 2 & Dar. & 65 & 79 \\
\hline 3 & Ali. & 60 & 66 \\
\hline 4 & Zal. & 89 & 83 \\
\hline 5 & Eliz. & 90 & 83 \\
\hline 6 & Isal. & 97 & 89 \\
\hline 7 & Pol. & 79 & 79 \\
\hline 8 & Vic. & 97 & 89 \\
\hline
\end{tabular}

Tables 2 and 3 provide the summative EFL score for each student in two groups during both the F2F autumn term (September-December 2019) and the ERL spring term (March-June 2020). The final ratings summarize students' points out of 100 maximum for term tests, initiated classroom performance, quality of credit test answers, and participation in the University's virtual academic events in English. Students' names are reduced beyond recognition for ethical reasons.

Table 3. End-of-Term EFL Achievement Results in Group 2 (first-year students)

\begin{tabular}{|c|c|c|c|}
\hline № & Student & $\begin{array}{c}\text { Autumn 2019 } \\
\text { (F2F class) } \\
\text { term scores }\end{array}$ & $\begin{array}{c}\text { Spring 2020 } \\
\text { (ERL class) } \\
\text { term scores }\end{array}$ \\
\hline 1 & Nas. & 84 & 97 \\
\hline 2 & Tat. & 100 & 91 \\
\hline 3 & Oks. & 60 & 66 \\
\hline 4 & Kek. & 89 & 83 \\
\hline 5 & Kar. & 90 & 83 \\
\hline 6 & Pkar. & 97 & 89 \\
\hline 7 & Mar. & 87 & 90 \\
\hline 8 & Sek. & 83 & 87 \\
\hline 9 & Sol. & 83 & 84 \\
\hline 10 & Jul. & 86 & 95 \\
\hline 11 & Chtat. & 83 & 96 \\
\hline 12 & Lud. & 68 & 64 \\
\hline 13 & Ade. & 91 & 86 \\
\hline
\end{tabular}

As Table 2 indicates, three students in the second-year group earned higher scores during the ERL period than during the F2F class sessions, one remained at the same level, and four students' ratings decreased.

In the first-year group, seven students achieved higher scores during the remote period, while six slid down to more modest results. Nevertheless, no total drop in the results during the ERL period was observed in either group. These conflicting results can be explicated in various ways. On one hand, Generation $\mathrm{Z}$ students feel at home in the digital communication environment, according to numerous scholars [14, 15]. Moreover, young people of this generation "desire ... personal challenges to keep them involved" [30], which means that emergency situations, radical changes, and obstacles can help them mobilize their abilities and gain better results, despite the circumstances. On the other hand, although "zoomers" are ready to compete [31], under remote learning circumstances they are taken out of their customary physical competitive environment, so some may have partly lost their psychological drive, which would naturally be reflected in their academic outcomes. Moreover, individual psychological features may make the virtual environment unsuitable for teamwork [9]. Finally, we should not ignore the fact that transfer to remote language learning owing to the 2020 pandemic was rapid and spontaneous and, therefore, could have created unexpected stressful conditions for home study for some students.

Regardless, the student retention percentage, or COR, was $100 \%$, as no students dropped out at the end of the 
spring term.

\section{Conclusions}

This study represents one stage in the author's larger scale investigation of emergency remote foreign language teaching as a pedagogical management challenge. Although the present study is, by far, not representative, it does allow for some inferences about tertiary students' attitudes toward COVID-19 caused by the reformat of language learning classes. This paper presents the results of an empirical exploration of students' perceptions of learning under emergency remote circumstances.

Devoid of their customary in-person educational environment, the students managed to cope with learning tasks successfully under the ERL conditions. Nevertheless, some reactions were not expected. Predictably positive attitudes toward the CMC were not confirmed. The majority did not demonstrate enthusiastic loyalty to CMC as a possible future alternative to traditional F2F live learning. Undoubtedly unaware of scholarly studies indicating the true benefit from a blend of digital and traditional learning [32], the majority of the students intuitively spoke out in favor of blended learning as an acceptable future mode of study. To this effect, this study confirms the results of other investigations [17] about Generation Z that demonstrated that they do not devalue a college education in its traditional contact format. However, the survey results showed the desirability of certain administrative and pedagogical measures, as the responses suggest that during the conventional academic year, a flexible combination of contact with remote virtual lessons could be more widely integrated into the full-time day department academic year rather than limiting classes to either only the F2F structure or only the remote format, as students demonstrated psychological readiness for a combined format. Such an arrangement can settle issues of auditorium shortages, poorly scheduled logistics, time difficulties, and student and faculty fatigue.

In the ERL format, the most positive attitude was toward person-to-person interactive activities. Activities missed most from F2F classes were multi-sensory rich-in-cues tasks that are difficult, if not impossible, to reproduce in a remote format without time lag and cue losses. This means that multi-sensory communication and the immediacy of responses were very meaningful for the participants and non-compensatory under CMC conditions.

This study suggests the likelihood of a culturally determined perception of remote language learning by students. The high-context culture of Russian learners would have benefited from videoconferencing more than from the reduced bandwidth audio medium they used during the ERL period, which resulted in their nostalgic voting for F2F group discussions and pair work, despite the fact that both activities were practiced online during the ERL period. This suggests the need for some compensatory adjustments to counterbalance the deficit of communication interactivity.

The research confirmed conclusions made previously that to be effective, remote language learning classes cannot strive to replicate a contact class alone [33] but need to go further by creating a rich-in-cues communication milieu. It is desirable to apply user-friendly full-bandwidth audio-visual platforms rich in communication cues. If that is not possible, a complex combination of compensatory measures is needed to complement cue-lacking teaching platforms with supportive regular asynchronous communication tools (e.g., tutor-initiated informing; encouraging and explicating messages on social network platforms; provision of educational materials via the University platform; cloud or other technologies; and other compensatory techniques).

The significance of this study lies in the fact that it adds to revelations of immediate student reactions to ERL, spotlights Russian ethnic attitudes, and uncovers comparative value for students of particular language learning activities in their remote and contact implementation.

This study had two primary limitations, the first of which was the small scale of the survey. The scale could have been expanded, but the author was interested in feedback from the students with whom she had worked through Skype, applying her approaches and activities, rather than random RSUH students who might have worked with other messengers and whose instructors could have applied different techniques, as including those students would have made the results of this study inconsistent. The second limitation was the subjective selection of activities to choose from as multiple-choice responses offered in the questionnaire, which were limited to the teaching repertoire and style of the author.

From the prospect of future research, practically nothing is known yet about the effect of ERL on language learning outcomes, though such investigations may be coming soon. Investigations of optimal ratios of F2F and $\mathrm{CMC}$ in a course for resultative language learning are also needed.

\section{REFERENCES}

[1] December J., "Units of Analysis for Internet Communication," Journal of Computer-Mediated Communication, vol. 1, no. 4, 1996. DOI: https://doi.org/10.1111/j.1083-6101.1996.tb00173.x

[2] December J., "Notes on Defining of Computer-Mediated Communication,” CMC Magazine, 1997. http://www.dece mber.com/cmc/mag/1997/jan/december.html (accessed July 31, 2020). 
[3] Hunt D., Atkin D., Krishnan A., "The Influence of Computer-Mediated Communication Apprehension on Motives for Facebook Use," Journal of Broadcasting Electronic Media, vol. 56, no. 2, pp. 187-202, 2012.

[4] Papacharissi Z., Rubin A. M., "Predictors of Internet Use," Journal of Broadcasting \& Electronic Media, vol. 44, no. 2, pp. 175-196, 2000. DOI: https://doi.org/10.1207/s1550687 8jobem4402_2

[5] Parke K., Marsden N., Connolly C., "Lay Theories Regarding Computer-Mediated Communication in Remote Collaboration,” Open Praxis, vol. 9, no. 1, pp. 17-30, 2017. https://tinyurl.com/y29ukofc (accessed 5 August, 2020).

[6] Andersen R., Ponti M., "Participatory Pedagogy in an Open Educational Course: Challenges and Opportunities," Distance Education, vol. 35, no. 2, pp. 234-249, July 2014. DOI: $10.1080 / 01587919.2014 .917703$

[7] Howard C., "An Instructional Paradigm for the Teaching of Computer-Mediated Communication,” Instructional Science, vol. 40, no. 3, pp. 493-513, 2011. DOI: 10.1007/s11251-011-9187-0

[8] Caplan S. E., "A Social Skill Account of Problematic Internet Use,” Journal of Communication, no. 55, pp. 721736, 2005.

[9] Bergiel B. J., Bergiel E. B., Balsmeier P. W., "Nature of Virtual Teams: A Summary of Their Advantages and Disadvantages,” Management Research News, vol. 31, no. 2, pp. 99-110, 2008.

[10] Short J., Williams E., Christie B., "The Social Psychology of Telecommunications,” Wiley, 1976.

[11] Walther J., "Theories of Computer-Mediated Communication and Interpersonal Relations," in The SAGE Handbook of Interpersonal Communication (4th ed.), SAGE Publications, Inc., 2011, pp. 443-479, Chapter 14.

[12] Sproull L., Kiesler S., "Reducing Social Context Cues," Management Science, no. 32, pp. 1492-1512, 1985.

[13] Walther J., "Computer-Mediated Communication," Communication Research, vol. 23, no. 1, pp. 3-43, 1996. DOI: $10.1177 / 009365096023001001$

[14] Guberman D., Layow E., "Understanding and Motivating Generation Z Students," Lilly Conference "Designing Effective Teaching,” Purdue University, Bethesda, MD, 2017.

[15] Katz R., "How Gen Z Is Different, According to Social Scientists (and Young People Themselves)," Pacific Standard, 2019.https://psmag.com/ideas/how-gen-z-is-diffe rent-according-to-social-scientists (accessed August 5, 2020).

[16] Francis T., Hoefel F., "True Gen: Generation Z and Its Implications for Companies,” McKinsey \& Company, 2018. https://www.mckinsey.com/industries/consumer-packagedgoods/our-insights/true-gen-generation-z-and-its-implicatio ns-for-companies (accessed August 2, 2020).

[17] Gomez K., Mawhinney T., Kimberly B., "Welcome to Generation Z," Network of Executive Women, Deloitte, 2019. https://tinyurl.com/y55dxzep (accessed August 2, 2020).

[18] Hodges C., Moore S., Lockee B., Trust T., Bond A., “The
Difference Between Emergency Remote Teaching and Online Learning,” Educause Review, March 27, 2020. https://er.educause.edu/articles/2020/3/the-difference-betwe en-emergency-remote-teaching-and-online-learning (accessed July 10, 2020).

[19] Malik C., "Introductory Guide to Research in Computer Mediated Communication (CMC)," 2017-2021. https://www.mastersincommunications.com/research/comp uter-mediated-communication/ (accessed September 1, 2020).

[20] Daft R. L., Lengel R. H., "Organizational Information Requirements, Media Richness and Structural Design," Management Science, no. 32, pp. 554-571, 1986.

[21] Rutter D. R., “Communicating by Telephone,” Pergamon, 1987.

[22] "Meet Generation Z: Forget Everything You Learned About Millennials,” Sparks \& Honey, 2014. https://www.slideshar e.net/sparksandhoney/generation-z-final-june-17 (accessed August 4, 2020).

[23] Korzenny F., Bauer C., "Testing the Theory of Electronic Propinquity,” Communication Research, no. 8, pp. 479-498, 1981.

[24] Rovegno S., "Student Voice in Remote Language Learning," in Innovations in Education. Remote Teaching, British Council, 2019.

[25] Okdie B., Guadagno R., Bernieri F., Geers A., Mclarney-Vesotski A., "Getting to Know You: Face-to-Face Versus Online Interactions," Computers in Human Behavior, no. 27, pp. 153-159, 2011.

[26] Hall E., “Beyond Culture,” Doubleday, 1976.

[27] Brett J. M., Adair W., Lempereur A., Okumura T., Shikhirev P., Tinsley C., Lytle A., "Culture and Joint Gains in Negotiation,” Negotiation Journal, vol. 14, no. 1, pp. 61-85, 1998.

[28] Valitova A., Besson D., "Perception of Russian Employees' Culture by Western Managers of Western Subsidiaries in Russia. Emerald Publishing Ltd," Society and Business Review, vol. 13, no. 2, pp. 195-216, 2018. DOI: https://doi.org/10.1108/SBR-11-2017-0097

[29] Kets de Vries M., "The Anarchist Within: Clinical Reflections on Russian Character and Leadership Style," Human Relations, vol. 54, no. 5, pp. 585-627, 2001.

[30] Jones V. F., Jones L. S., “Comprehensive Classroom Management: Creating Communities of Support and Solving Problems,” (10th ed.), Pearson, 2013.

[31] Seemiller C., Grace M., "Generation Z: Educating and Engaging the Next Generation of Students,” About Campus, vol. 22, no. 3, pp. 21-26, 2017. DOI: 10.1002/abc.21293

[32] [32] Akbaba Y., Başkan, F. "How to merge courses via Skype? Lessons from an International Blended Learning Project.” Research in Learning Technology, vol. 25, 2017. Doi: http://dx.doi.org/10.25304/rlt.v25.1915

[33] Ismail N. S., Abu Bakar N. M., Wafa S. W., Wafa S. S., "Online Learning Challenges During Pandemic COVID-19 in Malaysian Higher Learning Institution,” Universal Journal of Educational Research, vol. 8, no. 12, pp. 71517159, 2020. DOI: 10.13189/ujer.2020.081282 